\title{
Phylogenetic composition of Prochlorococcus and Synechococcus in cold eddies of the South China Sea
}

\author{
Hongmei Jing, Hongbin Liu* \\ Division of Life Science, The Hong Kong University of Science and Technology, Clear Water Bay, Kowloon, \\ Hong Kong SAR, China
}

\begin{abstract}
Two mesoscale cyclonic eddies (CE I and CE II) occurred along the Vietnam coast in the South China Sea during summer 2007; CE I was in the decaying stage and CE II was in the intensifying stage. CE II was also influenced by the Mekong River plume. The upwelling effect of the 2 eddies on the phylogenetic diversity of Prochlorococcus and Synechococcus was investigated by clone library construction based on sequences of the internal transcribed spacer (ITS) region, with station SEATS in the oligotrophic basin as a comparison. Phylogenetic analysis revealed the presence of sequences affiliated with 3 Prochlorococcus clades (HLI, HL II \& LLIV) and 7 Synechococcus clades (II, III, VII, X, XV, XVI, and sub-cluster 5.2) from the various water bodies, with HLII Prochlorococcus and clade II Synechococcus being the dominant phylotypes. Multivariate analysis demonstrated that spatial distribution of the 2 genera was mostly explained by temperature, but also affected by salinity and chlorophyll a concentration. Upwelling of the nutrient-rich subsurface water at the center of the cold eddy resulted in a significant increase in the abundance of Synechococcus in the young and intensifying CE II, whereas Prochlorococcus dominated in the old and decaying CE I and the surrounding oligotrophic waters. It is intriguing that Synechococcus clades III, XV and XVI, which are known to contain chromatically adapting members, were most numerous in eddy and river plume influenced waters, where light quality changes might be expected, compared to the oligotrophic basin waters. The disparity in cyanobacterial phylogenetic composition between the 2 eddies clearly reflected the differing hydrographic dynamics and developmental stages of these eddy systems.
\end{abstract}

KEY WORDS: Prochlorococcus $\cdot$ Synechococcus $\cdot$ Cold eddy $\cdot$ South China Sea Resale or republication not permitted without written consent of the publisher

\section{INTRODUCTION}

Unicellular picocyanobacteria, Prochlorococcus and Synechococcus, the most abundant photosynthetic microorganisms in the global oceans, occupy a key position in the marine microbial food web and contribute significantly to global primary production (Partensky et al. 1999, Jardillier et al. 2010). Prochlorococcus are generally more abundant than Synechococcus by 1 to 2 orders of magnitude except in coastal and upwelling regions (Partensky et al. 1999). Although the 2 genera often co-occur, they have dif- ferent geographical distributions. Prochlorococcus are numerically dominant in the warm oligotrophic oceans (Campbell et al. 1994), whereas Synechococcus predominate in coastal and more temperate/ mesotrophic open oceans with wider global distribution (Partensky et al. 1999).

Despite the well documented importance of Prochlorococcus and Synechococcus in marine ecosystems, fine-scale discrimination of closely related groups or species within these 2 genera has been made possible only recently, based on the genetic information of the 16S/23S rRNA internal transcribed 
spacer (ITS) region (Rocap et al. 2002, Johnson et al. 2006, Zinser et al. 2006, Martiny et al. 2009, Malmstrom et al. 2010). Prochlorococcus is composed of multiple genetically and physiologically differentiated subgroups, including at least 6 closely related lightadapted subgroups which are distributed at different water depths (Rocap et al. 2002). High-light-adapted (HL) Prochlorococcus dominate in the surface mixed layer and can be further subdivided into HLI and HLII subgroups; whilst the low-light-adapted (LL) Prochlorococcus dominate in the deeper layer of the euphotic zone and comprise at least 4 ecotypes LLI, LL II, LL III and LLIV (Rocap et al. 2002). As for Synechococcus, at least 10 distinct lineages have been found so far (Rocap et al. 2002, Fuller et al. 2003), and even greater diversities were reported based on rpoC1, ntcA and petB genes (Mühling et al. 2005, Lindell et al. 2005, Mazard et al. in press). In addition, the distinct biogeographic distributions of the most common Synechococcus clades, I, II and IV, throughout the world's oceans have been documented (Zwirglmaier et al. 2008): clades I and IV dominate in temperate, coastal environments (Brown \& Fuhrman, 2005, Zwirglmaier et al. 2008) and clade II proliferates in subtropical/tropical environments (Fuller et al. 2006, Zwirglmaier et al. 2008) and off-shore, oligotrophic environments (Toledo \& Palenik 2003).

Upwelling in mesoscale cyclonic eddies pumps nutrients into the euphotic zone and thus affects the activities and composition of different microbial groups, especially the phytoplankton community (Vaillancourt et al. 2003, Bibby et al. 2008). During each summer, an offshore current is formed eastwards near the coast of Vietnam between $11^{\circ} \mathrm{N}$ and $14^{\circ} \mathrm{N}$ and induces cold-core eddies and open-ocean upwelling in the South China Sea (SCS) (Xie et al. 2003). The SCS is a large semi-enclosed marginal sea in the tropicalsubtropical western North Pacific. It is typically oligotrophic with shallow mixed layer and nutricline depths and low primary production (Liu et al. 2002). The Mekong River on the Indochina peninsula carries significant nutrient input into the southwestern SCS. Cyanobacteria are the major component of the picoplankton and hence key primary producers in the SCS (Jiao \& Yang 2002, Liu et al. 2007, Chen et al. 2009), but little information is available on the phylogenetic composition of Prochlorococcus and Synechococcus or of the effects of eddies on picocyanobacterial population dynamics. Therefore, we constructed ITS clone libraries from water samples collected from 2 cold eddies formed in the SCS during summer to investigate the phylogenetic diversity and population dynamics of picocyanobacterial communi- ties in various water masses and in response to cold eddy formation.

\section{MATERIALS AND METHODS}

\section{Sample collection}

Two cold-core cyclonic eddies, named cold eddy I (CEI) and cold eddy II (CEII), were formed in the western SCS during the GOE-2 cruise on board the RV 'Dongfanghong 2' from 10 August to 14 September 2007. These eddies are thought to occur as a result of the prevailing southwestern monsoon in summer (Hu et al. 2011). Satellite altimeter data were obtained from the Global Near Real-Time Sea Level Anomaly Data Viewer at the Colorado Center for Astrodynamics Research (CCAR, USA) to monitor the evolution of the eddies. Surface seawater was collected at 8 stations in the western SCS during the same cruise from 24 August to 7 September 2007 (Fig. 1). Seawater from the deep chlorophyll a (chl a) maximum (DCM) was also collected at Stns TS-1 and SEATS to examine the vertical distribution. Water samples were collected using a CTD-General Oceanic rosette sampler with Go-Flo bottles (SBE 9/17 plus, SeaBird). Between 1.2 and 2.41 of seawater were filtered on board sequentially through $3 \mu \mathrm{m}$ and $0.22 \mu \mathrm{m}$ pore-size polycarbonate membranes (47 mm diameter, Millipore). The membranes were stored at $-80^{\circ} \mathrm{C}$ until DNA extraction on land.

In addition, total chl a concentrations were measured by a Turner Designs fluorometer (Model Trilogy 040) and the abundance of Prochlorococcus, Synechococcus and heterotrophic bacteria were enumerated using a Beckon-Dickinson FACSCalibur cytometer (Chen et al. 2009). Samples for inorganic nutrients (nitrate+nitrite, phosphate and silicate) were filtered through $0.45 \mu \mathrm{m}$ cellulose acetate filters and measured immediately onboard using a low injection analyzer (Tri-223 autoanalyzer) and standard spectrophotometric methods (Pai et al. 1990).

\section{DNA isolation and amplification}

Total genomic DNAs were recovered from biomass collected with the $0.22 \mu \mathrm{m}$ filters by phenol:chloroform:isoamyl alcohol (25:24:1) extraction at $60^{\circ} \mathrm{C}$ after lysis with CTAB buffer containing RNase A $(10 \mathrm{mg}$ $\mathrm{ml}^{-1}$ ) and lysozyme $\left(50 \mathrm{mg} \mathrm{ml}^{-1}\right.$ ). Extracted DNAs were precipitated with isopropanol and then stored at $-80^{\circ} \mathrm{C}$. The environmental DNA subsequently served 


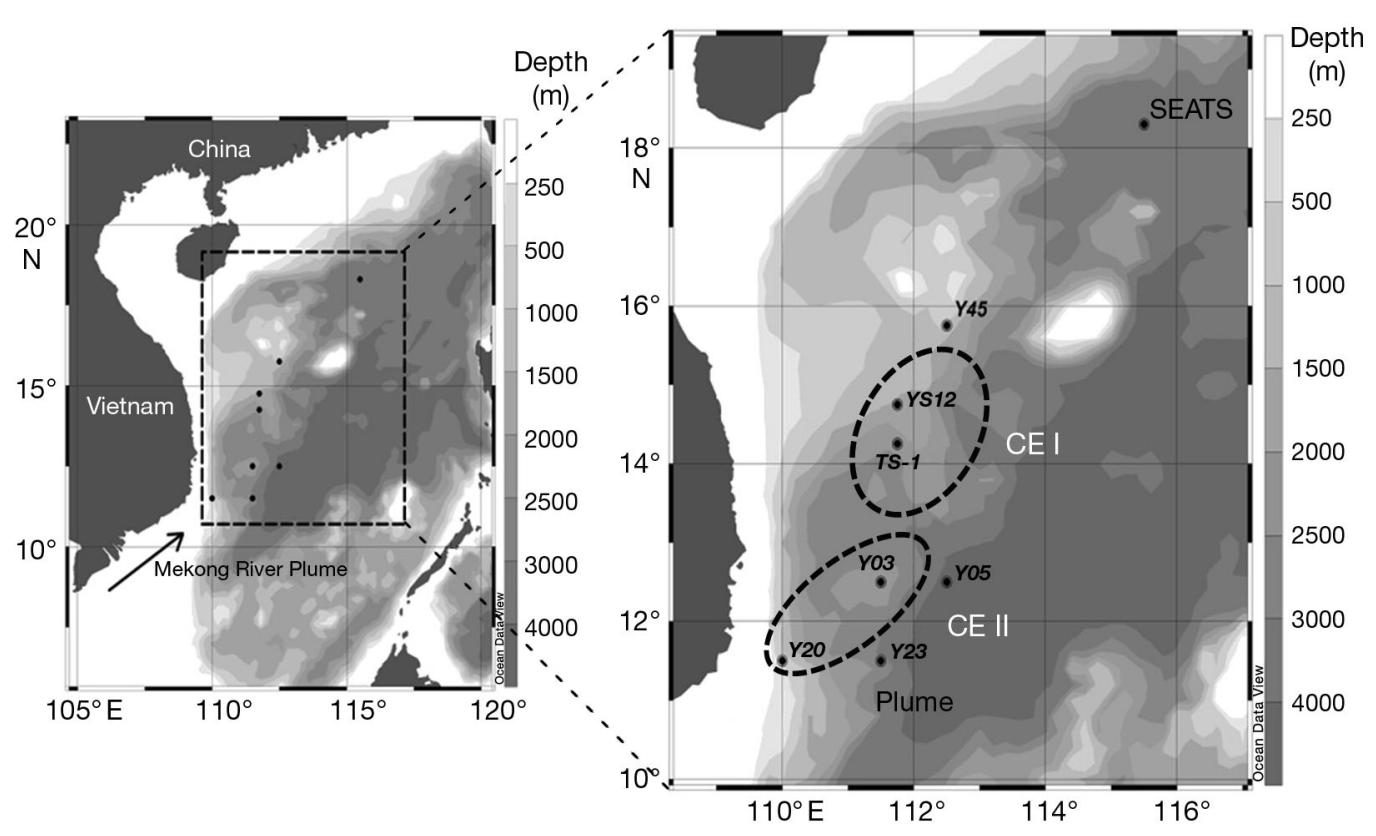

Fig. 1. Geographical location of the 2 cold eddies, occurring in the South China Sea off Vietnam during summer 2007. Sampling stations are shown, including those of cold eddy I (CEI) — In (TS-1), Edge (YS12) and Out (Y45) —, those of cold eddy II (CEII) - In (Y03), Edge (Y20) and Out (Y05) —, the Plume-affected station (Y23), and the control station of the Southeast Asia Time-Series Study (SEATS)

as template for amplification of a $1.5 \mathrm{~kb}$ DNA fragment encompassing the ITS region. This $1.5 \mathrm{~kb}$ fragment covered the distal portion of the 16S rRNA gene, the internal transcribed spacer region and the proximal region of the 23S rRNA gene. The picocyanobacterial specific primers used were 16S-1247F (5'-CGT ACT ACA ATG CTA CGG-3') (Rocap et al. 2002) and 23S-495R (5'-ACG GTT TCA GGT TCT ATT TCA CTC-3') (Jing et al. 2009). The PCR reaction was carried out with $50 \mu \mathrm{l}$ master mix including $5 \mu \mathrm{l}$ of 10x Buffer, $2 \mu \mathrm{l}$ of $\mathrm{MgCl}_{2}(25 \mathrm{mM}), 4 \mu \mathrm{l}$ of dNTPs $(2.5 \mathrm{mM}), 0.2 \mu \mathrm{l}$ of $\mathrm{Taq}$ polymerase $(5 \mathrm{U})$ and $1 \mu \mathrm{l}$ of each primer $(10 \mu \mathrm{M})$ with the following programme: $95^{\circ} \mathrm{C}$ for $3 \mathrm{~min} ; 30$ cycles of $95^{\circ} \mathrm{C}$ for $1 \mathrm{~min}, 55^{\circ} \mathrm{C}$ for $50 \mathrm{~s}, 72^{\circ} \mathrm{C}$ for $1 \mathrm{~min}$ final extension at $72^{\circ} \mathrm{C}$ for $10 \mathrm{~min}$. PCR products were stained with ethidium bromide and visualized on a $1 \%(\mathrm{w} / \mathrm{v})$ agarose gel, and a strong single band within the range of 1300 to $1600 \mathrm{bp}$ for each sample was revealed.

\section{Clone library construction and RFLP screening}

Independent PCR products from triplicate samples were pooled to reduce the chances of PCR artifacts and then purified using the PureLink ${ }^{\mathrm{TM}}$ Quick Gel Extraction Kit (Invitrogen). Purified amplicons were quantified with a NanoDrop ND-1000 spectrophotometer prior to cloning into the $\mathrm{pCR} 4.0$ vector using the TOPO TA cloning kit (Invitrogen). In total, 10 clone libraries were constructed. From each library 50 white colonies were randomly picked. The correct insertion was identified by direct amplification of the inserted DNA fragment with the original PCR primer set. Positive colonies were digested by 3 restriction enzymes, EcoRI, HaeIII and Hind III, at $37^{\circ} \mathrm{C}$ for $3 \mathrm{~h}$ in $10 \times$ Buffer M (Amersham Biosciences). The digestion products were separated by electrophoresis on a $3 \%$ $(\mathrm{w} / \mathrm{v})$ agarose gel. The restriction fragment length polymorphism (RFLP) patterns were visualized under UV radiation using a Universal Hood digital imaging system (Bio-Rad) of universal hood and were normalized against a $1 \mathrm{~kb}$ Plus DNA Ladder (Invitrogen).

\section{Sequencing and phylogenetic analysis}

For groups of colonies showing the same RFLP pattern, representative clones were randomly chosen for subsequent sequencing. Plasmid DNAs of all colonies showing distinct RFLP fingerprints were extracted, purified and then sequenced by an Applied Biosystems 3730 genetic analyzer using the BigDye Terminator Cycle Sequencing kit v3.1 (Applied Biosystems) with the QM13 primers.

BLAST searches of the GenBank database (www.ncbi.nlm.nih.gov) were performed to identify closely related sequences. We used $98 \%$ sequence 
similarity as a cutoff value. Sequences were also checked for chimeric properties by using Chimera CHECK from the RDP-II (Ribosomal Database Project II). Maximum Likelihood (ML) trees were generated using the Phylip 3.63 programme (http://evolution. genetics.washington.edu/phylip.html) for all sequences, which included selected representative sequences from GenBank following alignment using Clustal X 1.80. Bootstrap values were obtained with 1000 resamplings and clades with greater than $50 \%$ bootstrap value are shown on the nodes of branches.

\section{Statistical analysis}

Genetic diversity was assessed by the following indices: (1) number of clones examined; (2) number of different operational taxonomic units (OTUs); (3) Coverage, derived from the equation Coverage $=1-$ (N/total no. of clones), $\mathrm{N}$ being the number of clones occurring only once (Kemp \& Aller 2004); (4) Shannon-Weaver index $\left(H^{\prime}\right)$ and Simpson's Index of diversity $(1-D)$ (Krebs 1989). OTU was defined based on RFLP pattern and also the $98 \%$ cutoff value of ITS sequence similarity. Firstly, all clones showing the same RFLP pattern were considered as the same OTU. Then, representative clones of each RFLP pattern were sequenced, and all sequences obtained were multiple aligned for similarity comparison. If the sequence similarity of different RFLP patterns was $\geq 98 \%$, those RFLP patterns were grouped as the same OTU.

Detrended correspondence analysis (DCA) was carried out using CANOCO V4.5 (Biometrics-Plant Research International) to determine whether linear or unimodal species distribution models were more suitable for our data. In DCA, the correspondence analysis axes are divided into segments and the sample scores of the second axis are reassigned to be centered on the centroid to remove distortion. The length of the first DCA axis is 2.066 for the picocyanobacterial population. Therefore, canonical correspondence analysis (CCA), which assumes unimodal distributions of OTUs along environmental gradients, was performed in order to reveal the relationships between picocyanobacterial phylogenetic groups and environmental variables. Abiotic and biotic factors (see Table 1) were included as explanatory variables in the CCA and biplot scaling was used. The effects of high collinearity among those factors were removed by eliminating variables with variance inflation factor (VIF) $>20$, one at a time beginning with the variable with the highest VIF. Forward selection was then used to determine the minimum set of environmental variables that could explain the largest amount of variance in the community. The statistical significance of an explanatory variable added in the course of forward selection was tested with the Monte Carlo permutation test (999 permutations, $\mathrm{p} \leq 0.05$ ). In addition, correspondence analysis (CA) was carried out with CANOCO V4.5 to visualize the relationship of different stations with varied picocyanobacterial compositions.

\section{Nucleotide sequence accession numbers}

ITS sequences of all the clones obtained from this study were deposited in GenBank under accession numbers HQ849909 to HQ849928 for Prochlorococcus phylotypes and HQ849929 to HQ849994 for Synechococcus phylotypes.

\section{RESULTS}

\section{Physical and biological characteristics of the 2 eddies}

The cores of the 2 cold-core eddies (CE I and CE II) were located at $\sim 111.75^{\circ} \mathrm{E}, 14.25^{\circ} \mathrm{N}$ (TS-1) and $111.5^{\circ} \mathrm{E}, 12.5^{\circ} \mathrm{N}$ (Y03), respectively (Fig. 1). Based on the satellite altimetry, CE I was in the decaying stage and CEII was in the intensifying stage (Hu et al. 2011). The locations of sampling stations relating to the 2 eddies are indicated in Fig. 1 as well as in Table 1. In addition, Y23 is influenced by the Mekong River plume (referred to as 'Plume' thereafter) and the Southeast Asia Time-Series Study (SEATS) station located at the deep central basin serves as an oligotrophic gyre control station.

The studied area was generally oligotrophic, with inorganic nitrogen (nitrate + nitrite) consistently below the detection limit $\left(0.2 \mu \mathrm{mol} \mathrm{l}^{-1}\right)$ (Table 1$)$. The 2 eddies were characterized by low temperature, high salinity and high nutrient concentrations compared with the SEATS station, and the DCM in the core of CE I was apparently shallower than that in the SEATS. Much higher phosphate and chl a concentrations were associated with the core of the $2 \mathrm{CEs}$, whilst phosphate concentration was comparable between Plume and surface water of SEATS. Salinity in CE II was lower than in CEI, because the former is located geographically closer to the Mekong River plume.

Prochlorococcus cell densities ranged from $0.68 \times$ $10^{5}$ to $4.16 \times 10^{5}$ cells ml ${ }^{-1}$ with higher abundance in CEI than CEII, and also higher abundance in the 
Table 1. Physico-chemical characteristics of different water masses during the summer cruise in 2007 in the South China Sea. CE: cold eddy; Plume: Mekong River plume; SEATS: Southeast Asia Time-Series Study; Location: In = core of eddy, DCM = deep chlorophyll a maximum, Edge = margin of eddy, Out = outside eddy. Stations are shown in Fig. 1

\begin{tabular}{|c|c|c|c|c|c|c|c|c|c|c|}
\hline \multirow[t]{3}{*}{ Parameter } & \multicolumn{4}{|c|}{$-\mathrm{CE} \mathrm{I}-$} & \multicolumn{3}{|c|}{$-\mathrm{CE}$ II -} & \multirow{3}{*}{$\begin{array}{l}\text { Plume } \\
\text { Y23 }\end{array}$} & \multicolumn{2}{|c|}{$\longrightarrow$ SEATS } \\
\hline & In & DCM & Edge & Out & In & Edge & Out & & Surface & $\mathrm{DCM}$ \\
\hline & TS-1 & TS-1-DCM & YS12 & Y45 & Y03 & Y20 & Y05 & & & \\
\hline Latitude $\left({ }^{\circ} \mathrm{N}\right)$ & 14.25 & 14.25 & 14.75 & 15.75 & 12.50 & 11.50 & 12.50 & 11.50 & 18.30 & 18.30 \\
\hline Longitude $\left({ }^{\circ} \mathrm{E}\right)$ & 111.75 & 111.75 & 111.75 & 112.5 & 111.5 & 110 & 112.5 & 111.5 & 115.5 & 115.5 \\
\hline Sampling depth (m) & 5 & 45 & 5 & 5 & 5 & 5 & 5 & 5 & 5 & 65 \\
\hline Temperature $\left({ }^{\circ} \mathrm{C}\right)$ & 27.60 & 20.27 & 28.90 & 29.40 & 28.40 & 28.40 & 29.30 & 32.50 & 29.60 & 22.58 \\
\hline Salinity (PSU) & 34.10 & 34.48 & 34.10 & 33.40 & 33.30 & 33.90 & 32.80 & 32.50 & 33.8 & 34.45 \\
\hline $\mathrm{Chl} \mathrm{a}\left(\mu \mathrm{g} \mathrm{l}^{-1}\right)$ & 0.17 & 0.46 & 0.15 & 0.07 & 0.17 & 0.12 & 0.10 & 0.14 & 0.10 & 0.32 \\
\hline $\mathrm{SiO}_{3}{ }^{2-}\left(\mu \mathrm{mol} \mathrm{l} \mathrm{l}^{-1}\right)$ & 2.20 & 8.63 & 2.44 & 2.40 & 1.35 & 2.86 & 2.60 & 1.46 & 2.07 & 3.60 \\
\hline Phosphate $\left(\mathrm{nmol} \mathrm{l}^{-1}\right)$ & 24 & 408 & 14 & 11 & 20 & 13 & 10 & 8 & 9 & 145 \\
\hline $\begin{array}{l}\text { Prochlorococcus } \\
\left(\times 10^{5} \text { cells ml }^{-1}\right)\end{array}$ & 1.78 & 4.16 & 1.67 & 1.18 & 0.09 & 1.01 & 1.10 & 0.68 & 1.02 & 3.67 \\
\hline $\begin{array}{l}\text { Synechococcus } \\
\left(\times 10^{4} \text { cells ml }{ }^{-1}\right)\end{array}$ & 1.24 & 6.86 & 2.38 & 1.86 & 12.00 & 1.09 & 2.24 & 3.56 & 1.14 & 0.03 \\
\hline
\end{tabular}

DCM layer compared to surface waters (Table 1). Synechococcus was generally less abundant than Prochlorococcus but with substantially higher variability in cell numbers between stations and with the highest abundance appearing in the core of CEII. The plume was characterized by high Synechococcus and low Prochlorococcus cell abundance, whilst very low Synechococcus cell numbers ( 300 cells ml $^{-1}$ ) were detected at the DCM $(65 \mathrm{~m})$ of the SEATS station. The total abundance of picocyanobacteria was much higher in the core of CEI than CE II, and the lowest appeared in the Plume.

\section{Diversity and composition of ITS clone libraries}

Ten independent ITS clone libraries based on water samples collected from different water masses were constructed and each library exhibited distinct picocyanobacterial community structures after RFLP screening (Table 2). Generally, the cores of each eddy showed the lowest diversity and highest coverage, compared with other water masses of the same eddy. Within CEI, the diversity increased from the core to edge and reached the highest at the Out station. In contrast, the highest diversity appeared at the Edge station in the CE II eddy. In terms of the numbers of OTUs and diversity, these indices were higher in the surface waters compared to those in the DCM at the SEATS station; the opposite pattern was found in CEI.
A total of 500 positive clones were examined from all ITS clone libraries, and 117 clones representing the distinct RFLP patterns were subjected to phylogenetic analysis. All ITS sequences recovered from this study were identified as either Prochlorococcus or Synechococcus after being subjected to a BLAST search of the GenBank database. Overall, Prochlorococcus ( $52 \%$ of total clones) were slightly more abundant than Synechococcus (48\% of total clones).

\section{Phylogenetic composition of picocyanobacteria}

Maximum likelihood trees were constructed to reveal the detailed relationship between the obtained sequences and previously deposited sequences from the GenBank database. All of our phylotypes fell into known marine Prochlorococcus and Synechococcus clades (Figs. $2 \& 3$ ). Both high-light- and low-light-

Table 2. Composition and diversity analysis of all the clone libraries based on the sequences of the internal transcribed spacer (ITS). Operational taxonomic units (OTUs) were defined based on the restriction fragment length polymorphism pattern and also the $98 \%$ cutoff value of ITS sequence similarity. $H^{\prime}$ : Shannon-

Weaver index; $1-D$ : Simpson's Index. See Table 1 for other abbreviations

\begin{tabular}{|c|c|c|c|c|c|c|}
\hline Station & $\begin{array}{l}\text { No. of } \\
\text { examined }\end{array}$ & $\begin{array}{l}\text { clones } \\
\text { sequenced }\end{array}$ & $\begin{array}{l}\text { No. of } \\
\text { OTUs }\end{array}$ & $\begin{array}{c}\text { Coverage } \\
(\%)\end{array}$ & $H^{\prime}$ & $1-D$ \\
\hline CE I-In (TS-1) & 50 & 10 & 7 & 86 & 0.46 & 0.14 \\
\hline CE I-DCM (TS-1-DCM) & 50 & 10 & 9 & 82 & 0.97 & 0.18 \\
\hline CE I-Edge (YS12) & 50 & 14 & 13 & 74 & 1.03 & 0.26 \\
\hline CE I-Out (Y45) & 50 & 16 & 16 & 68 & 1.11 & 0.32 \\
\hline CE II-In (Y03) & 50 & 6 & 3 & 94 & 0.44 & 0.06 \\
\hline CE II-Edge (Y20) & 50 & 16 & 18 & 64 & 1.10 & 0.36 \\
\hline CE II-Out (Y05) & 50 & 9 & 10 & 80 & 0.57 & 0.20 \\
\hline Plume (Y23) & 50 & 12 & 12 & 76 & 0.96 & 0.24 \\
\hline SEATS-Surface & 50 & 17 & 15 & 70 & 1.12 & 0.30 \\
\hline SEATS-DCM & 50 & 7 & 6 & 88 & 0.80 & 0.12 \\
\hline
\end{tabular}


adapted Prochlorococcus were recovered from our study falling into 3 ecotypes: HLI, HLII and LLIV (Fig. 2). The majority of our Prochlorococcus OTUs, 44 out of 51, belonged to the HLII ecotype; 2 OTUs recovered from In and Out of CE I clustered with HL I ecotype; 3 OTUs obtained from the DCM of SEATS and CEI and 2 from the surface of Stn Out of CEI grouped with the low-light-adapted Prochlorococcus strains MIT9313 and MIT9303 (LLIV).

Synechococcus exhibited more complex composition in this study. Clones were distributed into 6 clades of sub-cluster 5.1 (II, III, VII, X, XV and $\mathrm{XVI}$ ) and each clade comprised OTUs recovered from both surface waters and the DCM (Fig. 3). In addition, 1 OTU from surface waters of the core of CE I grouped with Synechococcus WH8007 and fell into sub-cluster 5.2. The Synechococcus clade II was the major group, accounting for $39.4 \%$ of the total 66 sequences; 13 OTUs were closely related to clade XV, 10 fell into clade VII, and the rest were distributed between clades III, $\mathrm{X}$ and XVI.

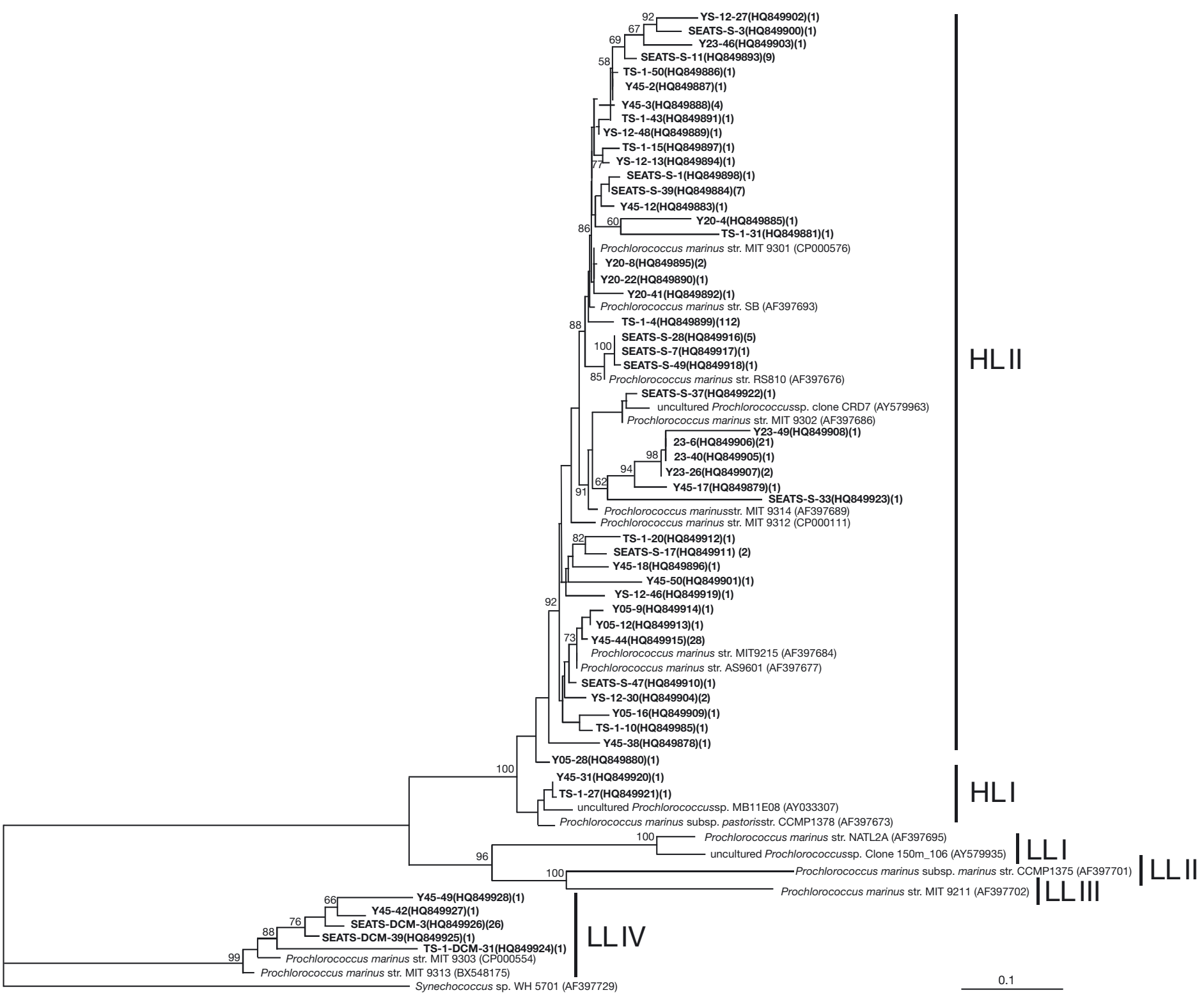

Fig. 2. Phylogenetic relationships among marine Prochlorococcus spp. based on maximum likelihood analysis of internal transcribed spacer (ITS) sequence data (ca. 1000 positions). Sequence codes in bold are derived from our study, and their abundance is indicated in parentheses; the prefixes denote stations where the sequences were obtained. The scale bar represents 0.1 nucleotide changes per position. High-light-adapted (HL) and low-light-adapted (LL) Prochlorococcus ecotypes are indicated 


\section{Distribution of picocyanobacteria in different water masses}

A distinct composition of Prochlorococcus and Synechococcus communities was observed in the different water masses. HL II Prochlorococcus was the most abundant Prochlorococcus group in all samples with the exception of the DCM at the SEATS station, which was composed exclusively of LLIV ecotypes
(Fig. 4a). However, whilst HLII OTUs dominated exclusively in the surface of both eddies, HLI and LLIV OTUs were also found in CE I, albeit in low proportions.

Synechococcus communities exhibited a more complex distribution pattern than Prochlorococcus. Synechococcus clade II was the only clade present in all water samples and was more abundant in the surface samples than in samples from the DCM (Fig. 4b).

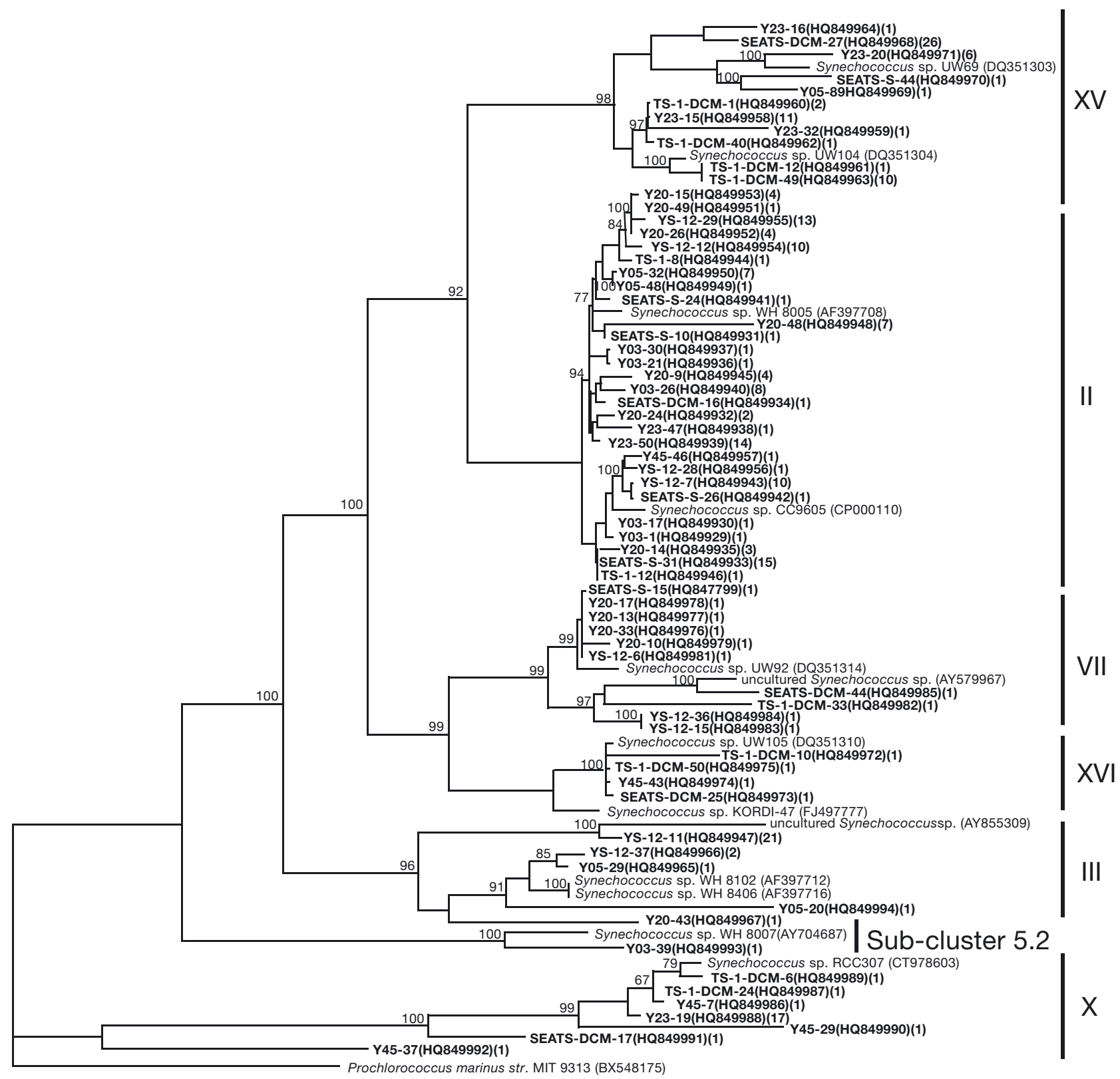

0.1

Fig. 3. Phylogenetic relationships among marine Synechococcus spp. based on maximum likelihood analysis of internal transcribed Spacer (ITS) sequence data (ca. 1160 positions). Roman numerals mark clades of Synechococcus sub-cluster 5.1. See

Fig. 2 for further details 

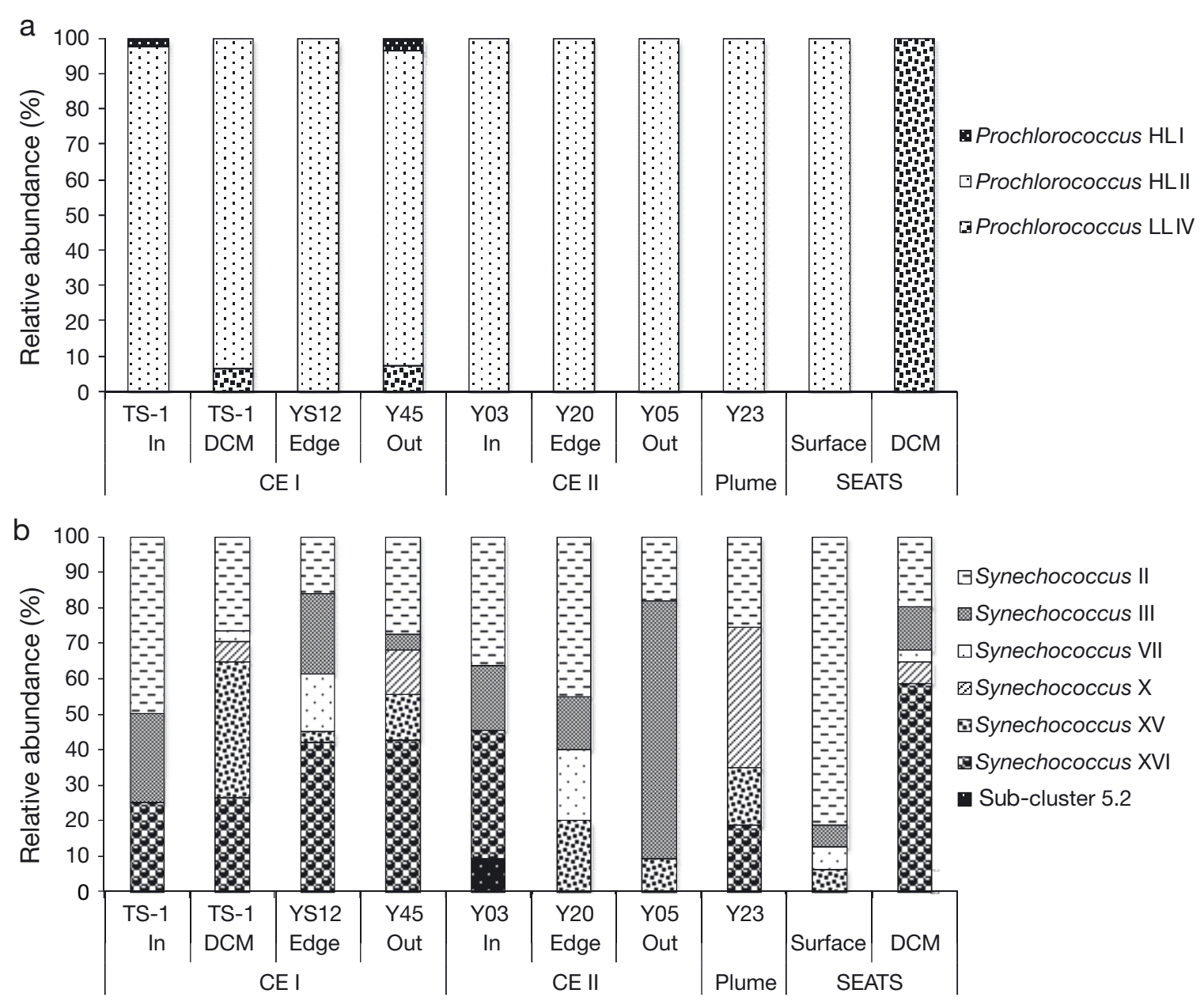

Fig. 4. Relative abundance of different phylogenetic groups of (a) Prochlorococcus and (b) Synechococcus at each station, reflected by the number of clones belonging to the 3 Prochlorococcus ecotypes and 7 Synechococcus clades in each clone library. CE: cold eddy; DCM: deep chlorophyll a maximum; SEATS: Southeast Asia Time-Series Study; HL: high-light-adapted; LL: low-light-adapted. See Table 1 for other abbreviations

The surface and DCM of the SEATS station was dominated by clade II and clade XVI OTUs, respectively. In contrast, clade XV was the major group at the DCM of CEI. Clade X was most abundant in water affected by the Mekong River plume and also occurred in low relative abundance in the 2 DCM samples. In the core of CEI, clade II had the highest relative abundance, whilst clade XVI became the most abundant phylotype in both the Edge and Out waters. Clades II and XVI were also the major groups in the core of CEII, whilst a significant increase in relative abundance of clade III was found outside CE II. OTUs of sub-cluster 5.2 were only detected in the Out waters of CE I and In waters of CE II.

Ordination analysis was carried out using the OTU matrix recovered from each station and the environmental variables listed in Table 1 . After excluding factors with VIF $>20,3$ variables - chl $a$, tempera- ture and salinity - were used for CCA. Temperature has close negative correlations with $\mathrm{chl}$ a $(\mathrm{r}=$ $-0.9147)$ and salinity $(r=-0.7790)$. According to the values of $\lambda_{\mathrm{A}}$, which represent the variance that each variable explains in the model during forward selection, temperature $\left(\lambda_{\mathrm{A}}=0.21\right)$ and chl $a\left(\lambda_{\mathrm{A}}=0.15\right)$ explained more of the total variance than salinity $\left(\lambda_{\mathrm{A}}\right.$ $=0.03)$ and were closely associated with the first $(\mathrm{r}=$ $0.8016)$ and the second $(r=0.8475)$ axes, respectively. The sum of all eigenvalues indicated an overall variance of 0.980 in the data set and the total variance that could be explained by environmental variation accounted for 0.689 , as indicated by the sum of all canonical eigenvalues. The first axis represents $23.9 \%$ of the variance explained by the environmental variables. Species-environmental correlations were high, indicating a significant relationship between picocyanobacterial communities 
and environmental variables. Biplot scaling of CCA based on the canonical axes 1 and 2 demonstrated the relationship between picocyanobacterial phylogenetic groups and environmental factors (Fig. 5): the 2 high-light-adapted Prochlorococcus groups clustered together, while LLIV Prochoorococcus showed its association with high salinity; Synechococcus groups showed a broader distribution and were influenced more by temperature and chl a (nutrient condition), with clade X located far from any other clades. In addition, CA exhibited the intersample relationship (Fig. 6): the picocyanobacterial community in Plume (upper right of Fig. 6), which was influenced by the freshwater discharge, was very distinct from those in other water masses; water samples from the DCM with high chl a and salinity, were separated from those collected in the surface; samples from the cores and edges of both CEs were closely distributed, but they were distant from those of Out waters.

\section{DISCUSSION}

\section{Phylogeny and distribution of picocyanobacteria}

Phylogenetic diversity amongst the 2 genera obtained from our study was similar to a previous report from the SCS based on rpoC1 gene sequences,

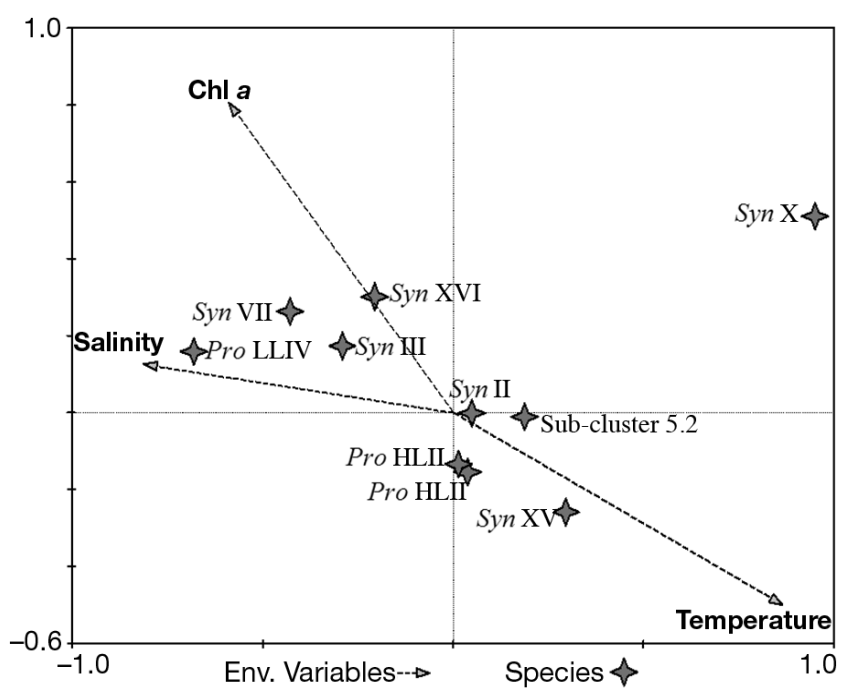

Fig. 5. Canonical correspondence analysis (CCA) biplot showing the relationship between different picocyanobacterial phylogenetic groups and environmental (env.) factors with the abiotic data set as explanatory variables. Syn: Synechococcus; Pro: Prochlorococcus; HL: high-light-adapted; LL: low-light-adapted; roman numerals identify clades of Synechococcus which showed that picocyanobacteria in both surface waters and at $80 \mathrm{~m}$ depth were composed of HL II Prochlorococcus and clade II Synechococcus (Ma et al. 2004). However, the considerable phylogenetic diversity within the 2 predominant clades, HLII Prochlorococcus and clade II Synechococcus, was augmented by the presence of HLI and LLIV Prochlorococcus genotypes and Synechococcus clades III, XV and XVI genotypes. These enhanced inter- and intra-clade diversities in response to eddy perturbations could enhance resistance or resilience to external perturbation (Hughes \& Stachowicz 2004).

HL II Prochlorococcus was the predominate group in all our subtropical water samples with the exception of the DCM at SEATS, which was composed exclusively of the LLIV ecotype. This is consistent with the fact that HLII dominates subtropical and tropical regions whilst HLI is more abundant at temperate latitudes (Zwirglmaier et al. 2008). Unlike that of SEATS, the DCM of CEI, which was shallower $(45 \mathrm{~m})$ than that of SEATS $(65 \mathrm{~m})$ was dominated by HLII Prochlorococcus, presumably reflecting significant water mixing caused by the upwelling of the eddy. Similar mixing likely explains the presence of HLII Prochlorococcus genotypes extending their distribution to the base of the euphotic zone in the Red Sea (West et al. 2001, Zwirglmaier et al. 2008). Similarly, HLII Prochlorococcus was the only lineage

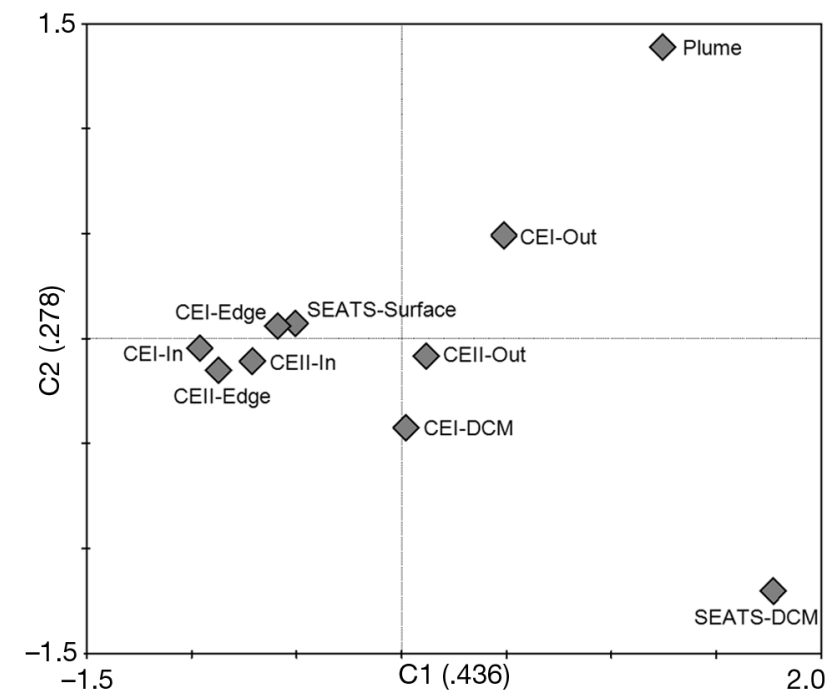

Fig. 6. Correspondence analysis (CA) biplot showing the distribution pattern of different sampling stations. Distances between station points give an indication of the similarity of picocyanobacterial taxonomic compositions in different water masses. CE: cold eddy; DCM: deep chlorophyll a maximum; SEATS: Southeast Asia Time-Series Study. See

Table 1 for abbreviations 
detected in both surface waters and at $80 \mathrm{~m}$ depth in the SCS in winter (Ma et al. 2004).

Synechococcus exhibited more dramatic population dynamics and diversity than Prochlorococcus in our study. Most of our sequences belong to Synechococcus sub-cluster 5.1, with only one sequence falling into sub-cluster 5.2. The latter contains mostly halotolerent strains isolated from coastal waters that possess phycocyanin but lack phycoerythrin; whilst the former is the dominant group within the euphotic zone of both open-ocean and coastal waters (Olson et al. 1990, Ferris \& Palenik 1998) and have an elevated salt requirement for growth with phycoerythrin as their major light-harvesting pigment (Waterbury et al. 1986, Rocap et al. 2002).

The major Synechococcus clades detected in our study have been reported with distinct distributions by other investigators (Partensky et al 1999, Zwirglmaier et al 2008, Mazard et al 2011). Clade II is one of the most abundant and widely distributed clades that is found in greatest abundance in the upper euphotic zone of subtropical oceanic waters (Toledo \& Palenik 2003, Zwirglmaier et al. 2008). This clade is always phylogenetically closely related to clade XV, which can use ammonium for growth (Ahlgren \& Rocap 2006). The fact that clade II Synechococcus was the major component in all our samples is in agreement with its dominant distribution in subtropical/tropical latitudes. The presence of lineages with the capability of chromatic adaptation (clades III, XV and XVI), i.e. containing strains that are able to alter their relative ratio of accessory pigments, phycourobilin and phycoerythrobilin, according to the spectral quality of light they receive (Palenik 2001, Ahlgren \& Rocap 2006), potentially reflects the highly dynamic environment induced by mesoscale eddies.

CCA analysis demonstrated that the community variations of both Prochlorococcus and Synechococcus in the different water masses in our study were related to temperature, salinity and chl a. This is consistent with the well-established finding that Prochlorococcus dominate in the subtropical oligotrophic oceans (Goericke \& Welschmeyer 1993, Campbell et al. 1994), whilst Synechococcus are usually more abundant under intermediate nutrient conditions (Liu et al. 1997, 1998). Spatial distribution profiles of Prochlorococcus appear mostly influenced by physical parameters, such as light and temperature (Zwirglmaier et al. 2008, Jameson et al. 2010), but relationships to salinity have not been documented. The inclusion of a low-salinity plume and high-salinity upwelling waters in our study, forming a clear salinity gradient, suggests that salinity is an important environmental variable in this regard.

\section{Effect of cyclonic eddies}

Upwelling of cold-core eddies is very important in supplying nutrients to surface waters in oligotrophic oceans. The fact that chl $a$ in the centers of both eddies was elevated above background levels indicates favorable in situ growth conditions for phytoplankton. Similar to what is found in the subtropical North Pacific gyre, Prochlorococcus are the most abundant autotrophic picoplankton in the South China Sea during summer (Liu et al. 2007). On the other hand, Synechococcus, which are able to respond quickly to nutrient pulses (Glover et al. 1988) and could increase their abundance along a nutrient gradient (Campbell et al. 1997, CavenderBares et al. 2001), were more abundant in the South China Sea during winter when the prevailing NE monsoon deepens the mixed layer depth (Liu et al. 2007). Our results show that the cores of CEI and CEII contained different abundances of Prochlorococcus and Synechococcus. This may reflect the fact that the 2 cold eddies were in different development stages; CEI was formed on 28 July and was in the decaying stage during our sampling period (24 to 28 August), whilst CE II was formed 1 mo later and was in the intensifying stage when we sampled there (3 to 7 September), according to the satellite altimeter data (Zhang et al. 2009, Hu et al. 2011). The biological responses are affected by a combination of the timing, magnitude and duration of nutrient inputs, which vary with eddy intensity and age (Benitez-Nelson \& McGillicuddy 2008). The predominance of Prochlorococcus in CEI reflects the decaying stage of the eddy, while the dramatic increase of Synechococcus abundance in CEII indicates the acceleration of upward flux of inorganic nutrients from the deeper layer as a result of the formation of the eddy (Fig. 2). It is also possible that a parcel of water with traces of the river plume, as inferred by relatively low salinity, was wrapped in by CEII. The increased percentage of Synechococcus in the DCM layer relative to that in surface waters of CE I may be an indicator that the nutrient-rich subsurface water did not reach the surface as the eddy was in its decaying stage. On the other hand, the near-absence of Synechococcus in the DCM layer of SEATS can be simply explained by the fact that the depth of the layer was below the optimal growth depth of Syne- 
chococcus. This depth is typically shallower than that of Prochlorococcus due to some major differences in their absorption of visible light resulting from their unique pigment composition - particularly in the enhanced ability to absorb green light by Synechococcus (Ting et al. 2002).

Although both eddy-induced upwelling and freshwater discharge injected nutrients to the surface mixed layer, they created distinct hydrographical conditions that can lead to distinct taxonomic composition of picocyanobacterial communities. The relatively higher percentage of Synechococcus in the plume-influenced water agrees with the general distribution pattern of high abundance of Synechococcus associated with coastal river plumes contrasting to Prochlorococcus dominated oligotrophic water (Paul et al. 2000, Liu et al. 2004). Higher proportions of potentially chromatically adapting genotypes within clades III, XV and XVI appeared in the CEI (50 to $68 \%$ ), CE II (35 to $81 \%$ ) and Plume (34\%) compared to the oligotrophic basin station SEATS $(12 \%)$. This supports the idea that chromatically adaptable strains could be better suited to the variable light environment and changing water chemistry inherent within the eddies.

Cyclonic eddies are biologically productive and can induce large variations in the biogeochemical characteristics of oligotrophic regions (McGillicuddy et al. 1998). The upwelling of deep nutrientrich waters into the euphotic zone can trigger not only an increase in primary production but also a shift in microbial community structure. The absolute magnitude and rate of nutrient injection at any point within an eddy's life cycle may have a significant impact on the composition of the microbial community (Rii et al. 2008, Brown et al. 2008, Chen et al. 2011). Future studies should monitor the various developmental stages of eddies in order to elucidate upwelling effects on the water chemistry and any subsequent changes in microbial community structure.

Acknowledgements. The authors thank Xiamen University for providing the opportunity to attend the cruise. Thanks to Prof. Minhan Dai and Jianyu $\mathrm{Hu}$ for providing the hydrographic and nutrient data and Ms. Xihan Chen for collecting the DNA samples. Insightful comments and language editing provided by Dr. Eva Lindström and 2 anonymous reviewers greatly improved the quality of the paper. This work was supported by Hong Kong RGC (RGF grants 661809 and 661610) and the TUYF Charitable Trust (TUYF10SC08) to H.L. The support of the National Basic Research Program ("973" Program) of China through grant 2009CB421203 and the Natural Science Foundation of China through grant 40730846 is also acknowledged.

\section{LITERATURE CITED}

Ahlgren NA, Rocap G (2006) Culture isolation and cultureindependent clone libraries reveal new marine Synechococcus ecotypes with distinctive light and N physiology. Appl Environ Microbiol 72:7193-7204

> Benitez-Nelson CR, McGillicuddy DJ Jr (2008) Mesoscale physical-biological-biogeochemical linkages in the open ocean: an introduction to the results of the E-Flux and EDDIES programs. Deep-Sea Res II 55:1133-1138

Bibby TS, Gorbunov MY, Wyman KW, Falkowski PG (2008) Photosynthetic community responses to upwelling in mesoscale eddies in the subtropical North Atlantic and Pacific Oceans. Deep-Sea Res II 55:1310-1320

> Brown MV, Fuhrman JA (2005) Marine bacterial microdiversity as revealed by internal transcribed spacer analysis. Aquat Microb Ecol 41:15-23

Brown SL, Landry MR, Selph KE, Yang EJ, Rii YM, Bidigare RR (2008) Diatoms in the deserts: plankton community response to a mesoscale eddy in the subtropical North Pacific. Deep-Sea Res II 55:1321-1333

Campbell L, Nolla HA, Vaulot D (1994) The importance of Prochlorococcus to community structure in the central North Pacific Ocean. Limnol Oceanogr 39:954-961

Campbell L, Liu H, Nolla HA, Vaulot D (1997) Annual variability of picoplankton in the subtropical North Pacific Ocean at Station ALOHA. Deep-Sea Res I 44: $167-192$

Cavender-Bares KK, Karl DM, Chisholm SW (2001) Nutrient gradients in the western North Atlantic Ocean: relationship to microbial community structure and comparison to patterns in the Pacific Ocean. Deep-Sea Res I 48: 2373-2395

Chen BZ, Liu HB, Landry MR, Dai MH, Huang BQ, Sun J (2009) Close coupling between phytoplankton growth and microzooplankton grazing in the western South China Sea. Limnol Oceanogr 54:1084-1097

> Chen X, Liu H, Weinbauer M, Chen B, Jiao N (2011) Viral dynamics in the surface water of the western South China Sea in summer 2007. Aquat Microb Ecol 63: $145-160$

Ferris MJ, Palenik B (1998) Niche adaptation in ocean cyanobacteria. Nature 396:226-228

Fuller NJ, Marie D, Partensky F, Vaulot D, Post AF, Scanlan DJ (2003) Clade-specific 16S ribosomal DNA oligonucleotides reveal the predominance of a single marine Synechococcus clade throughout a stratified water column in the Red Sea. Appl Environ Microbiol 69: 2430-2443

> Fuller NJ, Tarran GA, Yallop M, Orcutt KM, Scanlan DJ (2006) Molecular analysis of picocyanobacterial community structure along an Arabian Sea transect reveals distinct spatial separation of lineages. Limnol Oceanogr 51: 2515-2526

> Glover HE, Prézelin BB, Campbell L, Garside C (1988) A nitrate-dependent Synechococcus bloom in surface Sargasso Sea water. Nature 331:161-163

> Goericke R, Welschmeyer NA (1993) The marine prochlorophyte Prochlorococcus contributes significantly to phytoplankton biomass and primary production in the Sargasso Sea. Deep-Sea Res I 40:2283-2294

> Hu JY, Gan JP, Sun ZY, Zhu J, Dai MH (2011) Observed three-dimensional structure of a cold eddy in the southwestern south china sea. J Geophys Res 116, C05016, doi:10.1029/2010JC006810 
Hughes AR, Stachowicz JJ (2004) Genetic diversity enhances the resistance of a seagrass ecosystem to disturbance. Proc Natl Acad Sci USA 101:8998-9002

> Jameson E, Joint I, Mann NH, Mühling M (2010) Detailed analysis of the microdiversity of Prochlorococcus populations along a North-South Atlantic Ocean transect. Environ Microbiol 12:156-171

> Jardillier L, Zubkov MV, Pearman J, Scanlan DJ (2010) Significant $\mathrm{CO}_{2}$ fixation by small prymnesiophytes in the subtropical and tropical northeast Atlantic Ocean. ISME J 4:1180-1192

> Jiao NZ, Yang YH (2002) Ecological studies on Prochlorococcus in the China Seas. Chin Sci Bull 47:1243-1250

> Jing H, Zhang R, Pointing SB, Liu HB, Qian PY (2009) Genetic diversity and temporal variation of the marine Synechococcus community in the subtropical coastal waters of Hong Kong. Can J Microbiol 55:311-318

Johnson Z, Zinser ER, Coe A, McNulty NP, Woodward EMS, Chisholm SW (2006) Niche partitioning among Prochlorococcus ecotyopes along ocean-scale environmental gradients. Science 311:1731-1740

Kemp PF, Aller JY (2004) Bacterial diversity in aquatic and other environments: what 16S rDNA libraries can tell us. FEMS Microbiol Ecol 47:161-177

Krebs CJ (1989) Ecological methodology. Harper \& Row, New York, NY

> Lindell D, Penno S, Al-Qutob M, David E, Korpal T, Lazar B, Post AF (2005) Expression of the N-stress response gene $n t c A$ reveals N-sufficient Synechococcus populations in the oligotrophic northern Red Sea. Limnol Oceanogr 50: 1932-1944

> Liu H, Nolla HA, Campbell L (1997) Prochlorococcus growth rate and contribution to primary production in the equatorial and subtropical North Pacific Ocean. Aquat Microb Ecol 12:39-47

> Liu H, Campbell L, Landry MR, Nolla HA, Brown SL, Constantinou J (1998) Prochlorococcus and Synechococcus growth rates and contributions to production in the Arabian Sea during the 1995 Southwest and Northeast Monsoons. Deep-Sea Res II 45:2327-2352

> Liu KK, Chao SY, Shaw PT, Gong GC, Chen CC, Tang TY (2002) Monsoon-forced chlorophyll distribution and primary production in the South China Sea: observations and a numerical study. Deep-Sea Res I 49:1387-1412

> Liu H, Dagg MJ, Campbell L, Urban-Rich J (2004) Picophytoplankton and bacterioplankton in the Mississippi River plume and adjacent waters in the Gulf of Mexico. Estuaries 27:147-156

Liu H, Chang J, Tseng CM, Wen LS, Liu KK (2007) Seasonal variability of picoplankton in the northern South China Sea at the SEATS station. Deep-Sea Res II 54: 1602-1616

> Ma Y, Jiao NZ, Zeng YH (2004) Natural community structure of cyanobacteria in the South China Sea as revealed by rpoC1 gene sequence analysis. Lett Appl Microbiol 39:353-358

Malmstrom RR, Coe A, Kettler GC, Martiny AC, Frias-Lopez J, Zinser ER, Chisholm SW (2010) Temporal dynamics of Prochlorococcus ecotypes in the Atlantic and Pacific Oceans. ISME J 4:1252-1264

> Martiny AC, Tai AP, Veneziano D, Primeau F, Chisholm SW (2009) Taxonomic resolution, ecotypes and the biogeography of Prochlorococcus. Environ Microbiol 11:823-832

Mazard S, Ostrowski M, Partensky F, Scanlan DJ (in press)
Multi-locus sequence analysis, taxonomic resolution and biogeography of marine Synechococcus. Environ Microbiol

McGillicuddy DJ, Robinson AR, Siegel DA, Jannasch HW and others (1998) Influence of mesoscale eddies on new production in the Sargasso Sea. Nature 394: 263-266

Mühling M, Fuller NJ, Millard A, Scanlan DJ, Post AF, Wilson WH, Mann NH (2005) Genetic diversity of marine picoplankton (Synechococcus) blooms and covariance of the associated virioplankton population. Environ Microbiol 7:499-508

> Olson RJ, Chisholm SW, Zettler ER, Armbrust EV (1990) Pigments, size, and distribution of Synechococcus in the North Atlantic and Pacific Oceans. Limnol Oceanogr 35: 45-58

$>$ Pai SC, Yang CC, Riley JP (1990) Effects of acidity and molybdate concentration on the kinetics of the formation of the phosphoantimonylmolybdenum blue complex. Anal Chim Acta 229:115-120

Palenik B (2001) Chromatic adaptation in marine Synechococcus strains. Appl Environ Microbiol 67:991-994

Partensky F, Blanchot J, Vaulot D (1999) Differential distribution and ecology of Prochlorococcus and Synechococcus in oceanic waters: a review. In: Charpy L, Larkum AWD (eds) Marine Cyanobacteria. Bull Inst Oceanogr Monaco 19:457-475

> Paul JH, Alfreider A, Wawrik B (2000) Micro- and macrodiversity in $r b c L$ sequences in ambient phytoplankton populations from the southeastern Gulf of Mexico. Mar Ecol Prog Ser 198:9-18

Rii YM, Brown SL, Neicioli F, Kuwahara V, Dickey T, Karl DM, Bidigare RR (2008) The transient oasis: nutrientphytoplankton dynamics and particle export in Hawaiian Lee cyclones. Deep-Sea Res II 55:1275-1290

Rocap G, Distel DL, Waterbury JB, Chisholm SW (2002) Resolution of Prochlorococcus and Synechococcus ecotypes by using 16S-23S ribosomal DNA internal transcribed spacer sequences. Appl Environ Microbiol 68: 1180-1191

Ting CS, Rocap G, King J, Chisholm SW (2002) Cyanobacterial photosynthesis in the oceans: the origins and significance of divergent light-harvesting strategies. Trends Microbiol 10:134-142

> Toledo G, Palenik B (2003) A Synechococcus serotype is found preferentially in surface marine waters. Limnol Oceanogr 48:1744-1755

> Vaillancourt RD, Marra J, Seki MP, Parsons ML, Bidigare RR (2003) Impact of a cyclonic eddy on phytoplankton community structure and photosynthetic competency in the subtropical North Pacific Ocean. Deep-Sea Res I 50: 829-847

Waterbury JB, Watson SW, Valois FW, Franks DG (1986) Biological and ecological characterization of the marine unicellular cyanobacterium Synechococcus. Can Bull Fish Aquat Sci 214:71-120

West NJ, Schonhuber WA, Fuller NJ, Amann RI, Rippka R, Post AF, Scanlan DJ (2001) Closely related Prochlorococcus genotypes show remarkably different depth distributions in two oceanic regions as revealed by in situ hybridization using 16S rRNA-targeted oligonucleotides. Microbiology 147:1731-1744

Xie SP, Xie Q, Wang DX, Liu WT (2003) Summer upwelling in the South China Sea and its role in regional climate variations. J Geophys Res 108:1-17 
Zhang Y, Sintes E, Chen J, Zhang Y, Dai M, Jiao N, Herndl GJ (2009) Role of mesoscale cyclonic eddies in the distribution and activity of Archaea and Bacteria in the South China Sea. Aquat Microb Ecol 56:65-79

Zinser ER, Coe A, Johnson Z, Martiny AC, Fuller NJ, Scanlan DJ, Chisholm SW (2006) Prochlorococcus ecotype abundances in the North Atlantic Ocean as revealed by

Editorial responsibility: Eva Lindström,

Uppsala, Sweden an improved quantitative PCR method. Appl Environ Microbiol 72:723-732

Zwirglmaier K, Jardillier L, Ostrowski M, Mazard S and others (2008) Global phylogeography of marine Synechococcus and Prochlorococcus reveals a distinct portioning of lineages among oceanic biomes. Environ Microbiol 10:147-161

Submitted: June 6, 2011; Accepted: November 9, 2011

Proofs received from author(s): January 17, 2012 